\title{
Innovations in STEM education: the Go-Lab federation of online labs
}

\author{
Ton de Jong ${ }^{*}$, Sofoklis Sotiriou ${ }^{2}$ and Denis Gillet ${ }^{3}$
}

\author{
* Correspondence: \\ a.j.m.dejong@utwente.n \\ ${ }^{1}$ Faculty of Behaviourial, \\ Management \& Social sciences, \\ University of Twente, PO Box \\ 2177500AE Enschede, The \\ Netherlands \\ Full list of author information is \\ available at the end of the article
}

\begin{abstract}
The Go-Lab federation of online labs opens up virtual laboratories (simulation), remote laboratories (real equipment accessible at distance) and data sets from physical laboratory experiments (together called "online labs") for large-scale use in education. In this way, Go-Lab enables inquiry-based learning that promotes acquisition of deep conceptual domain knowledge and inquiry skills, with the further intent of interesting students in careers in science. For students, Go-Lab offers the opportunity to perform scientific experiments with online labs in pedagogically structured learning spaces. Go-Lab's inquiry learning spaces (ILSs) structure the students' inquiry process through an inquiry cycle and provide students with guidance in which dedicated (and connected) scaffolds for inquiry processes play a pivotal role. Teachers can create and adapt inquiry learning phases and the associated guidance in an ILS through a simple wiki-like interface and can add scaffolds and tools to an ILS using a straightforward drag and drop feature. Teachers can also adapt scaffolds and tools (e.g., change the language or the concepts available in a concept mapper) through an "app composer". In creating ILSs, teachers are supported by scenarios and associated defaults ILSs that can be used as a starting point for development. In addition, teachers are offered a community framework to disseminate best practices and find mutual support. For lab-owners, Go-Lab provides open interfacing solutions for easily plugging in their online labs and sharing them in the Go-Lab federation of online labs. In its first year, Go-Lab created ILSs for thirteen online labs from different lab providers, including renowned research organizations (e.g., CERN, ESA) that participate in the consortium. The design of these inquiry learning spaces has been evaluated through mock-ups and prototypes with students and teachers. More advanced and later versions will be evaluated and validated in large scale pilots. The sustainability of Go-Lab will come from the opportunity for the larger science education community to add new online labs and share ILSs. An open and Web-based community will capitalize on the "collective intelligence" of students, teachers, and scientists.
\end{abstract}

Keywords: Online laboratories; Inquiry learning; Classroom activities; Open social applications

\section{Introduction}

In order to guarantee prosperity, the world needs young people who are skillful in, and enthusiastic for, science ${ }^{a}$ and regard science as their future career field. To ensure this, large-scale initiatives are needed that engage students in interesting and motivating science experiences. In this context, initiatives at the policy level worldwide recommend taking an inquiry approach to education, involving teachers as the main stakeholders,

\section{焦 Springer}

(c) 2014 de Jong et al.; licensee Springer. This is an Open Access article distributed under the terms of the Creative Commons Attribution License (http://creativecommons.org/licenses/by/4.0), which permits unrestricted use, distribution, and reproduction in any medium, provided the original work is properly credited. 
and ensuring the commitment of other stakeholders (e.g., science laboratories) (National Research Council, 2006; Rocard et al., 2007). In line with these recommendations, the Go-Lab project has as its goals encouraging young students to engage in science topics, to acquire scientific inquiry skills, and to experience the culture of doing science under motivating circumstances by undertaking active, guided, experimentation, carried out with more basic and top-level scientific facilities. Making science labs available online for this purpose is seen as one of the largest revolutions yet to come in our educational system (de Jong et al. 2013; Waldrop, 2013); involving teachers in this process to identify factors that influence practical use is seen as crucial to ensure a smooth embedding in the curriculum and daily lesson practice (see e.g., Plass et al., 2012). More concretely, Go-Lab will offer students and teachers a federation of virtual and remote laboratories and data-sets/ analysis tools, together referred to as "online labs"; it offers teachers an authoring facility to embed these online labs in pedagogically structured learning spaces, and provides students with instructional guidance and opportunities for social interaction alongside the online laboratories. This article describes the Go-Lab philosophy together with its initial results.

\section{Online laboratories}

Online labs are science labs offered through computer technology. The core activity in an online lab is an investigation (experimentation or exploration) with (physical or virtual) equipment or the possibility of working directly with the results of such an investigation (in the form of data sets). In an online lab, investigation material, physical or virtual, is manipulated, and the effects of this manipulation are observed in order to gain insight into the relationship between variables in the conceptual model underlying the online lab (de Jong, et al., 2013). We distinguish three types of online labs. In a virtual laboratory the investigation is performed by the student with simulated (virtual) equipment. In a remote laboratory the investigation is performed with physical equipment that is operated at a distance. In a dataset the manipulation has been done by a third party, often a professional organization, and outcomes of these investigations can be inspected by the students. Datasets often come with dedicated analysis and visualization tools that help to organize and interpret the data.

An example of a virtual lab is depicted in Figure 1. In this lab, which presents the domain of buoyancy, students can go through different levels: they can start by manipulating just the density of objects, then there is a level where just the volume and mass (and thus density) of the solid object can be manipulated, a level where the density of the fluid can also be changed, a level on Archimedes' principle, and a level that also displays forces. The figure shows the lab's level on Archimedes' principle. In a virtual lab all elements, in this case tubes, balls, fluids, measuring scales, and so forth, are virtual. Virtual labs are present for many domains and often presented in online repositories such as PHET (Wieman et al. 2008) and there are several virtual labs on buoyancy (e.g., Künsting et al. 2013; Zhang et al. 2004).

An example of a remote lab can be seen in Figure 2. The figure shows the set-up of a chemistry experiment on the production of methyl orange. In this remote lab students can change the temperature and the inflow rate of different reagents and they can measure the concentration of methyl orange in the micro reactor (measured by the transparency of the solution as indicated by a UV/spectrophotometer and observable 


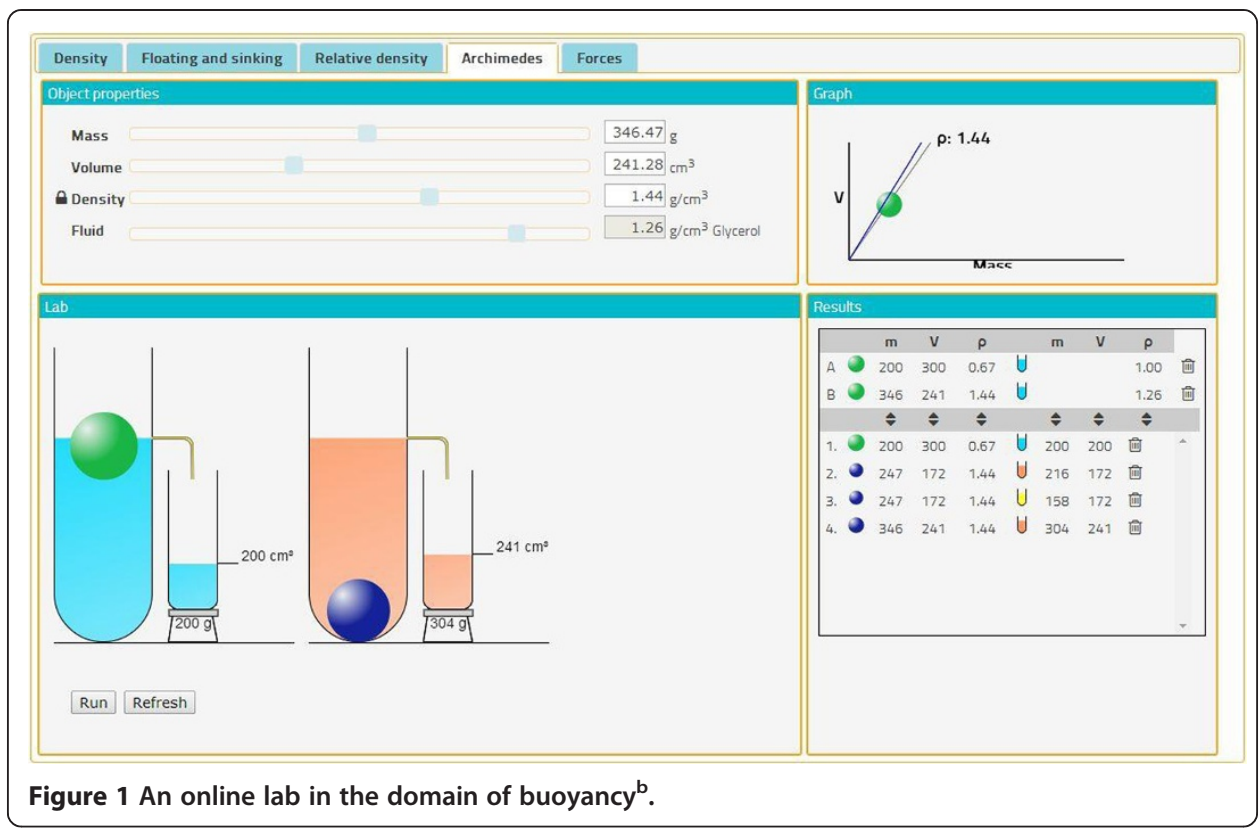

through a webcam). Through this experiment, students gain knowledge about the chemistry of acids and bases and the process of diazotization. This remote lab is located at the Free University of Amsterdam. An overview of the experiment, the design of a lesson series, and the experiences of teachers and students with this lab are reported in van Rens et al. (2013).

A lab that is based on a dataset is depicted in Figure 3. In this lab, called HYPATIA, data from the ATLAS detector (atlas.ch) at the Large Hadron Collider (LHC) at CERN are made available for students. Collisions that occur in the ATLAS detector produce particles that are visible as tracks that originate from the central point of the detector and pass through different layers of the detector. Students can inspect these tracks that

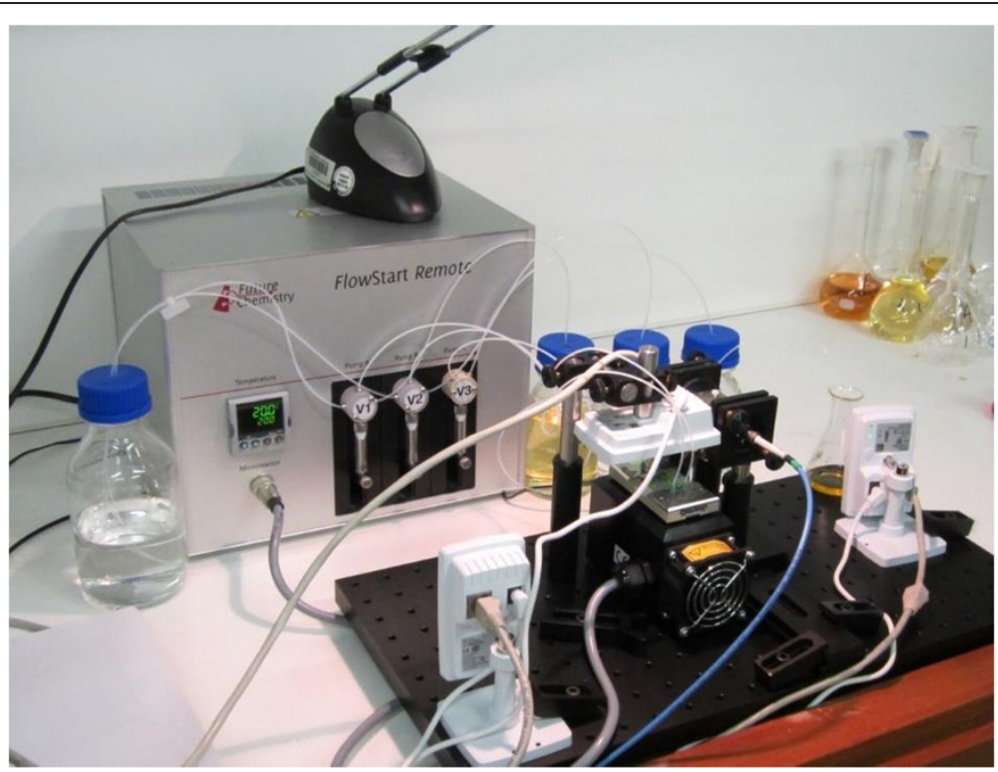

Figure 2 The "Methyl orange" remote lab (photo reprinted with permission) ${ }^{c}$. 


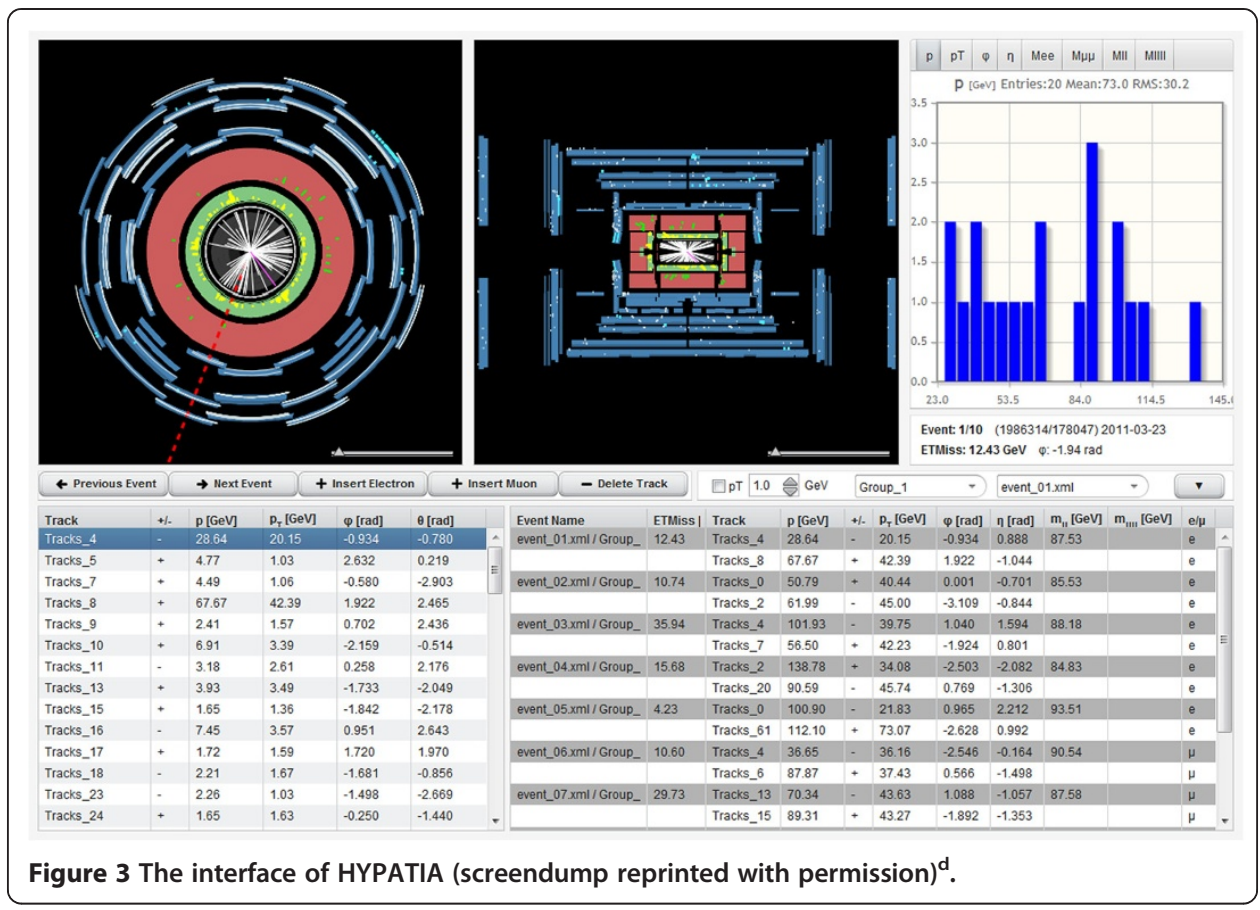

are displayed as datasets (showing the total momentum, the angles of the particles, etc.) or graphically visualized in the detector (see Figure 3). Clearly, students could never perform these experiments themselves but HYPATIA enables them to inspect "events" from the real detector (Kourkoumelis and Vourakis, 2014).

The Go-Lab pedagogical approach: the Inquiry learning Space

The central pedagogical approach adopted in Go-Lab is inquiry learning. In inquiry learning students follow a process in which investigations are pivotal. This means that information is not offered directly to students but needs to be extracted from an interaction with a phenomenon in the real world or with a model of the phenomenon. This investigation process is guided by a research question or hypothesis, requires interpretation of results and the formulation of conclusions, and the outcomes need to be communicated to others (National Science Foundation, 2000). We have chosen the (guided) inquiry approach because it has proven to be more effective than other lab approaches using cookbook procedures or discovery approaches (de Jong, et al., 2013).

All three types of lab described above provide students with the opportunity to carry out an inquiry process. However, just providing a lab does not suffice for an effective learning process. Research shows that in order for inquiry to be successful it needs to be combined with guidance; when guidance is available, an inquiry learning process leads to better conceptual knowledge than traditional instruction. This has been shown in large-scale studies over different subjects (see e.g., Eysink et al., 2009; Linn et al. 2006; Plass, et al., 2012) and is also the outcome of recent overview studies and metaanalyses (see e.g., Alfieri et al. 2011; Furtak et al. 2012). In a recent meta-analysis that focused specifically on inquiry learning with simulations, d'Angelo et al. (2014) concluded that students who learned with a simulation had better achievements than students who followed an alternative form of instruction and that adding guidance to a 
simulation, especially scaffolding, and using multiple representations further increased students' performance. If guidance is added, learning with online labs is often also more effective for acquiring conceptual knowledge than learning in real laboratories (de Jong, et al., 2013).

Guidance is the support that helps the learner in the process of inquiry in the online lab. In Go-Lab, guidance comes in two forms. First, the overall learning process is organized following an "inquiry cycle" that provides the learner with a set of phases. Second, specific forms of guidance are offered for each of the phases.

A basic Go-Lab inquiry cycle that includes all of the main elements but is still parsimonious enough to be able to work with was extracted on the basis of an extensive overview of inquiry cycles used in the literature. This cycle consists of the following phases: Orientation focuses on encouraging students' interest in the subject. In the orientation phase the main variables of the domain are introduced; the main outcome of this phase is an initial overview of the domain and the topics involved. Conceptualization is the phase in which students need to focus on one or more specific issues in the domain, in the form of one or more research questions or hypotheses. In general, a hypothesis is a statement in which a certain relation between independent and dependent variables is proposed, while a question does not state the direction of this relation. In the investigation phase, students create plans for experiments and perform the experiment, which may involve exploring the behavior of the online lab when guided by a question or performing purposeful experiments when they have created a hypothesis. The outcome of this phase is an "interpretation" of the data (the relations between variables). In the conclusion phase, students return to their original research questions or hypotheses and consider whether these are answered or supported by outcomes of the investigation. Discussion is sharing one's inquiry process and results with others and involves presenting and communicating findings and conclusions and reflecting upon one's own inquiry process.

Students can be given specific guidance within each of the inquiry phases. Within Go-Lab we have based this guidance on a typology of guidance introduced by de Jong and Lazonder (2014). The least intrusive way of guiding students is by limiting the number of choices they are given. These so-called process constraints can include the use of simplified models or interfaces, for example. Providing students with insight into their own learning process is also a non-intrusive kind of guidance. By means of a dashboard feature, students can be provided with a (graphical) overview of their inquiry actions (e.g., number and type of variables manipulated) or characteristics of their product (e.g., quality of a concept map). Based on the information on the dashboard (for an illustration, see later in this section) students may adapt their inquiry activities. Prompts are cues for students to carry out a certain action. They tell students that they should perform an action, so that they will not forget to do this on their own (e.g., "compare the results of the different experiments you did", or "did you consider measurement errors?"). Assignments are more specific prompts that explain to students what actions to perform. Heuristics give students general suggestions on how to perform a certain action or learning process. They can, for example, tell students to try out extreme values of variables to see how the model behaves under such circumstances. Finally, scaffolds are tools that help students perform a learning process by supporting the dynamics of the activities involved. 


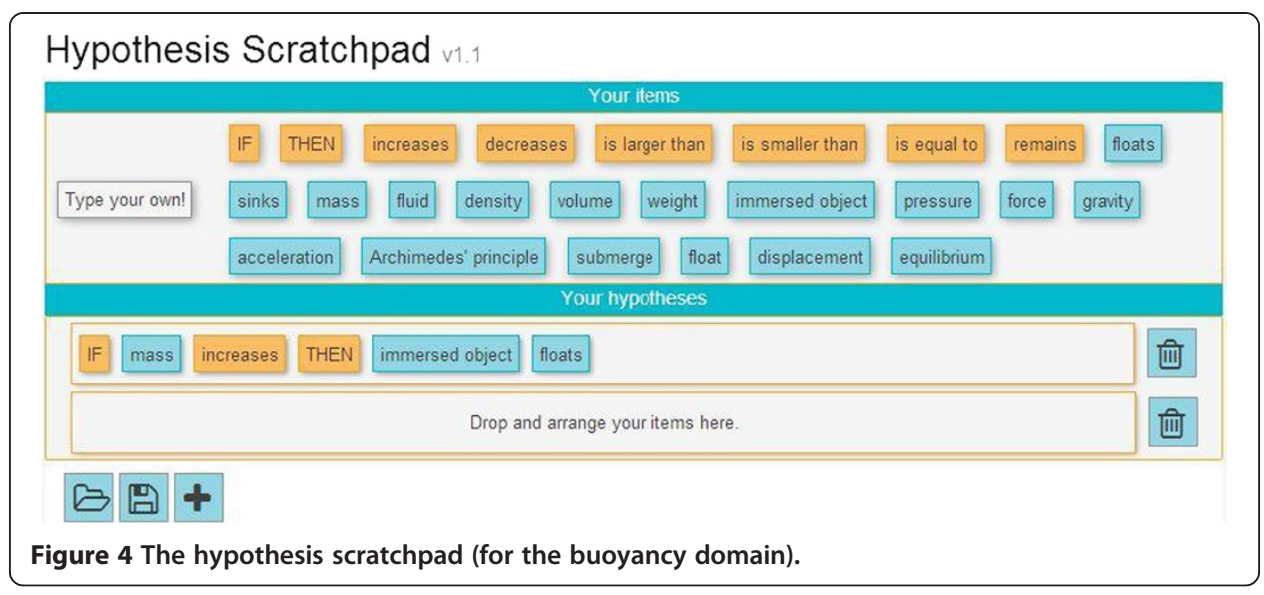

An example of a scaffold, the hypothesis scaffold, is shown in Figure 4. This tool based on van Joolingen and de Jong (1991) allows students to compose hypotheses by dragging and combining predefined terms or by using self-defined terms or sentences.

Another example is the Experiment Design Tool (EDT), shown in Figure 5. The EDT helps students to design unconfounded experiments and focuses especially on assisting students with using the "Control of Variables Strategy" (CVS, see Chen and Klahr, 1999). In this tool students can drag variables to three fields: "vary", "keep the same", and "observe/"measure". If a student drags two variables to the "vary" field a warning is displayed that explains why this may not be the best strategy to follow. When a student is satisfied with the selection of variables, the next tab (Design) offers the possibility of varying the values of the selected variables and noting the outcomes of experiments, the Run tab offers the opportunity to actually run the experiments in the lab.

In Go-Lab, the above elements come together in a learning environment that we have called an Inquiry Learning Space (ILS). In a Go-Lab ILS the inquiry cycle is presented in the form of tabs that students can cycle through (see Figure 6). A usability study with teachers and students showed a preference for this type of representation over a cyclic one (Law, 2013). Teachers can adapt the naming, sequencing, and presence of the phases to their personal preferences or (national) curriculum requirements (see the later section on authoring). For each phase in the cycle an ILS includes background material (domain information such as written text, videos, graphics, URLs, etc.). The

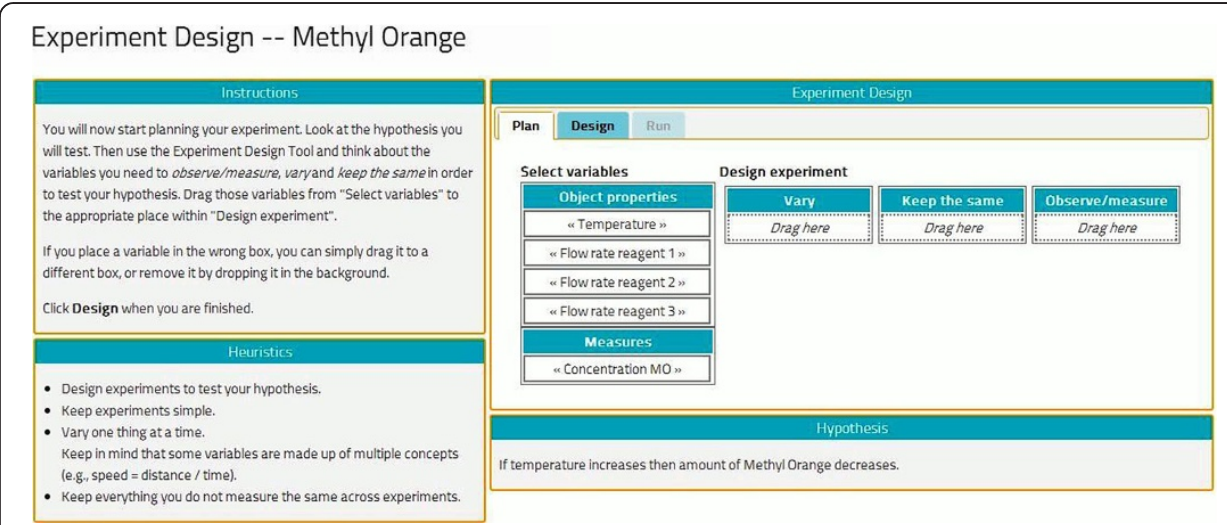

Figure 5 Experiment design tool (for the Methyl Orange domain). 

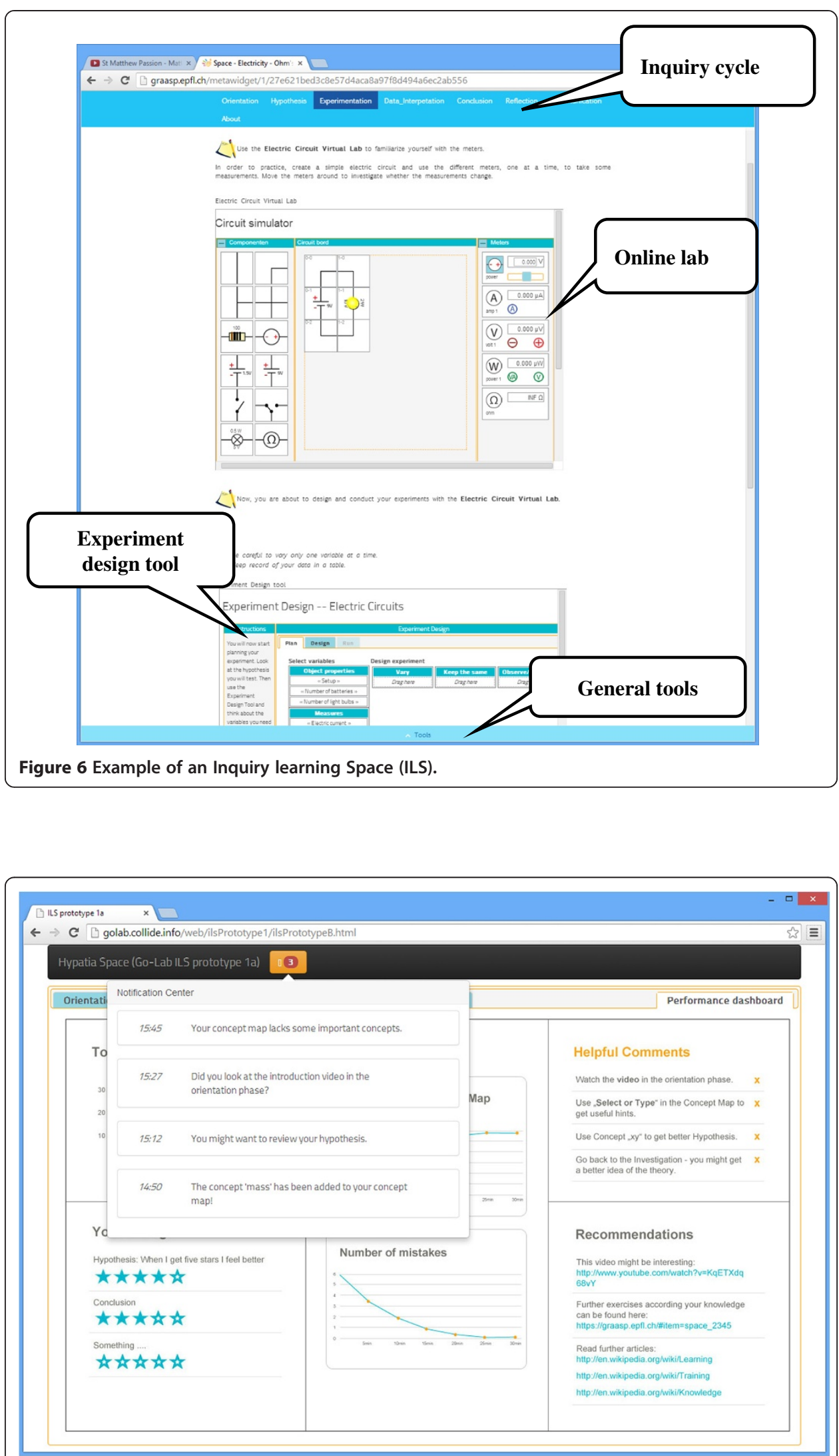

Figure 7 Mock-up of the dashboard in a Go-Lab ILS with automated alerts. 
diverse types of guidance are represented in different ways in the ILS. The dashboard functionality is implemented through a learning analytics service; students' actions are logged, graphically summarized and inspectable. Prompts, assignments, and heuristics are currently represented on the running page of each phase. Scaffolds, or apps (as we also call them), are currently the most prominent types of guidance and included in the ILS as tools. We have designed prototypes of the following scaffolds: a concept mapper (orientation phase), a hypothesis scratchpad and a questioning scratchpad (conceptualization phase), an experiment design tool (investigation phase), a data interpreter (investigation phase), and a conclusion scaffold (conclusion phase). Scaffolds that are currently under design are a measurement error tool (investigation phase), a reflection tool, and a reporting tool (both discussion phase). General tools, for example a calculator, are present in the bottom bar.

One of the phases of an ILS is shown in Figure 6. In this example, the student is in the investigation (here labelled "experimentation" by the author of the ILS) phase of an ILS based on a virtual electricity lab. In the example the student can design an experiment with the experiment design tool.

The different scaffolds function in an independent yet integrated way. This means, for example, that when a student in the conclusion tool wants to have access to hypotheses created with the hypothesis scratchpad or data sets for experiments, these are available within the conclusion tool. Another step of integration will be to create automatic alerts, for example, to tell a student that a concept that is in the concept map is not included in one of the student's hypotheses.

A development related to the scaffolds is to provide students with an automatic analysis of some of their products, for example by presenting them a comparison between the student's concept map and an expert concept map. This may lead to a dashboard that looks like the screendump in Figure 7. Here, students have access to overviews of their learning process and automatic feedback.

\section{The Go-Lab portal}

The Go-Lab portal (www.golabz.eu) is the main landing place for lab-owners and teachers. The Go-Lab portal consists of a number of elements and offers a series of functionalities. The core content of the Go-Lab portal is the repository of online labs (virtual, remote, and datasets). These labs can be searched on the basis of an extensive set of metadata that offer direct links, for example, to science curricula, language, educational objectives, level of interaction and difficulty of the lab. Moreover, the labs are organized according to a series of "big ideas" in science (see e.g., Harlen, 2010) that helps teachers to place each lab within a larger picture of the scientific field. A second core part of the Go-Lab portal is a large set of what we have called "apps". These may be dedicated scaffolds, such as the hypothesis scratchpad and the experiment design tool mentioned above, generic domain-specific tools (such as an interactive periodic table) or domain-independent generic tools (such as a calculator or a notepad). The third core element of the portal is a set of usable ILSs. Here a teacher may find complete inquiry learning spaces based on a specific lab that are ready to be used in a learning situation. The portal uses a "tile" interface in which labs, apps, and ILSs are depicted as tiles. Upon selecting a "tile" more information becomes available, and for an app, a preview of the app is accessible. Figure 8 shows a snapshot of the main page 


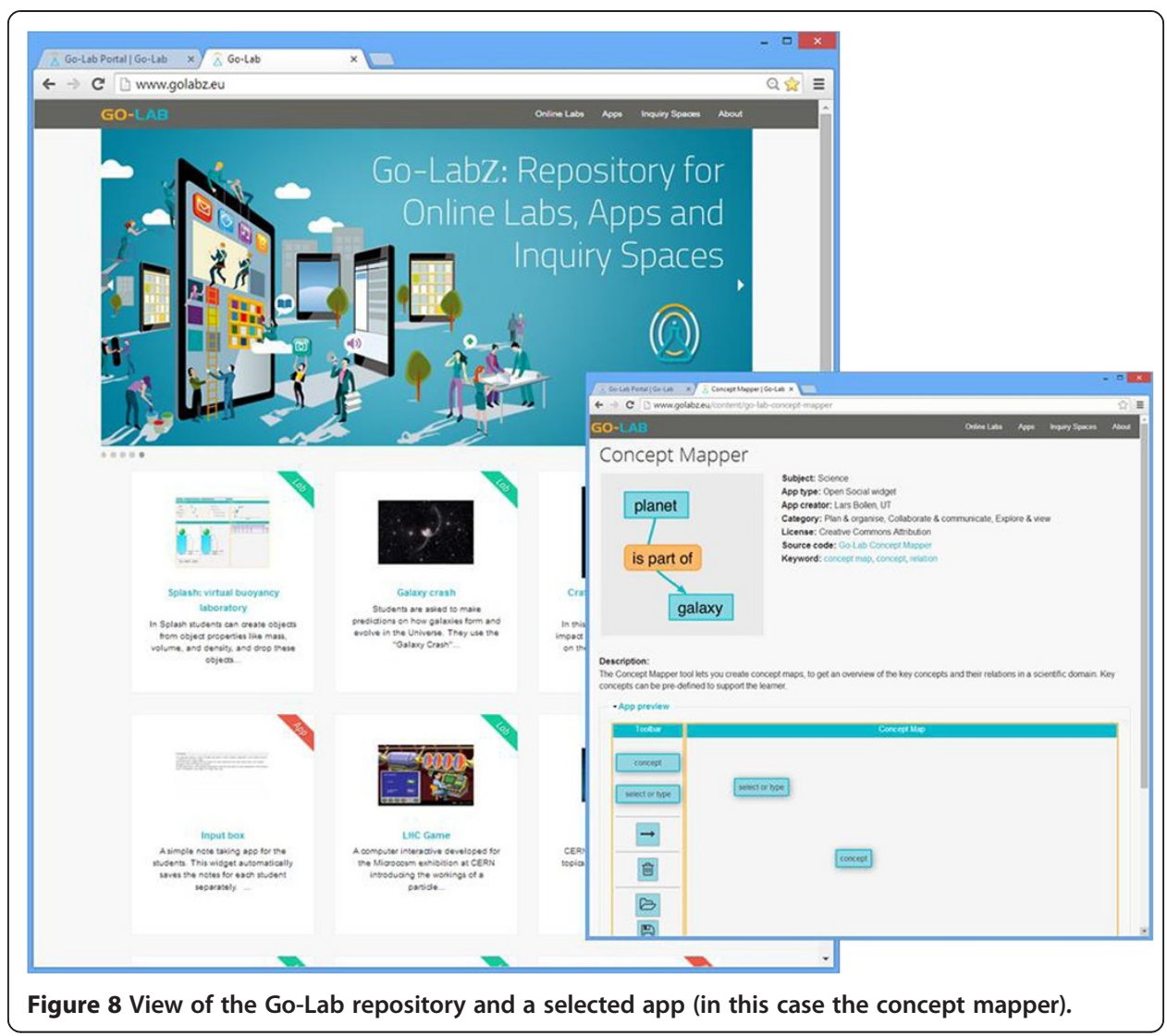

of the Go-Lab portal (left) that displays labs, apps, and inquiry spaces as tiles. Once one of these categories is selected, the user can make a refined search on the basis of a large set of metadata. After an element has been selected from the database it is displayed as is the example of the concept mapper scaffold to the right. The bottom part of this window shows an interactive demo of the selected scaffold/app (concept map).

The Go-Lab portal will also offer a series of additional facilities, such as a booking facility, a bartering platform (this platform enables the exchange of services and competencies) and access to the Go-Lab community. The development of the portal is based on a user-centered approach that involves users directly, beginning with the initial steps of the process. This process includes extended cycles of school-centred work. Teachers (and students) will continuously give feedback to the academic team about their experiences during the use of facilities in the Go-Lab portal This not only increases the teachers' motivation and gives weight to their practical experiences, but it also provides the necessary cross-links between design, development, and practice. Being part of a professional network will provide teachers with opportunities to enrich their practices and extend their professional context through cooperation within and between schools, universities, and frontier research institutions. The development of such a virtual learning community will be enhanced by the Go-Lab community support facilities, which will provide tools for community building and support, and will encourage cooperation between teachers, students, and researchers.

Finally, the Go-Lab portal gives access to the Go-Lab platform enabling ILS authoring as discussed in the next section. 


\section{Authoring inquiry learning spaces}

One of the facilities that sets Go-Lab apart from other online repositories (e.g., PhET, Wieman, et al., 2008) is that Go-Lab offers teachers the capability to create dedicated inquiry learning spaces. We support this process by proposing scenarios and lesson plans that help to design ILSs and combine them with off-line activities. Go-Lab also facilitates the sharing of these products in an online teacher community through the Go-Lab repository.

From a technical point of view, authoring in Go-Lab is extremely simple and straightforward. We assume that a user, most often a teacher, has decided on the domain/topic for which s/he wants to use an online lab. This can be a topic for which the teacher thinks that the teaching can be improved by taking a more inquiry-based approach or s/he can also be inspired by an online lab from the Go-Lab repository. This lab is then taken as the starting point for the Go-lab authoring process. Suppose the teacher has chosen the HYPATIA lab that is currently in the Go-Lab repository of labs. After selecting the lab, the teacher can read about this lab and follow the link to the lab to try it out. Figure 9 displays the description page of the HYPATIA lab and shows the button ("Create Inquiry Space") that gives access to the ILS authoring facility.

After having clicked the "Create Inquiry Space" button the teacher is transferred to the ILS platform (which is based on the Graasp platform, see further on) where the teacher sees as the default the phases from the Go-Lab inquiry cycle (see Figure 10; the

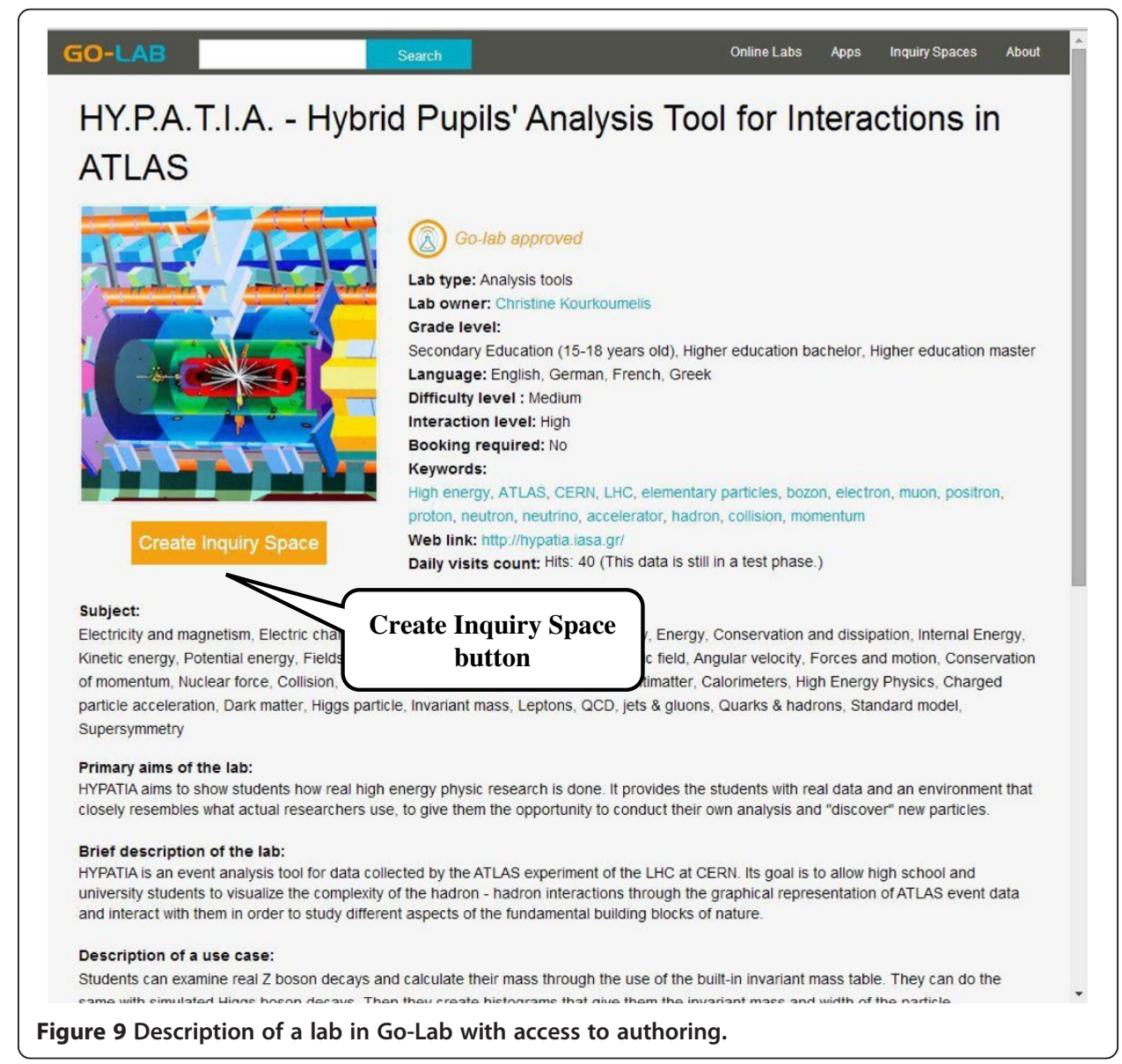




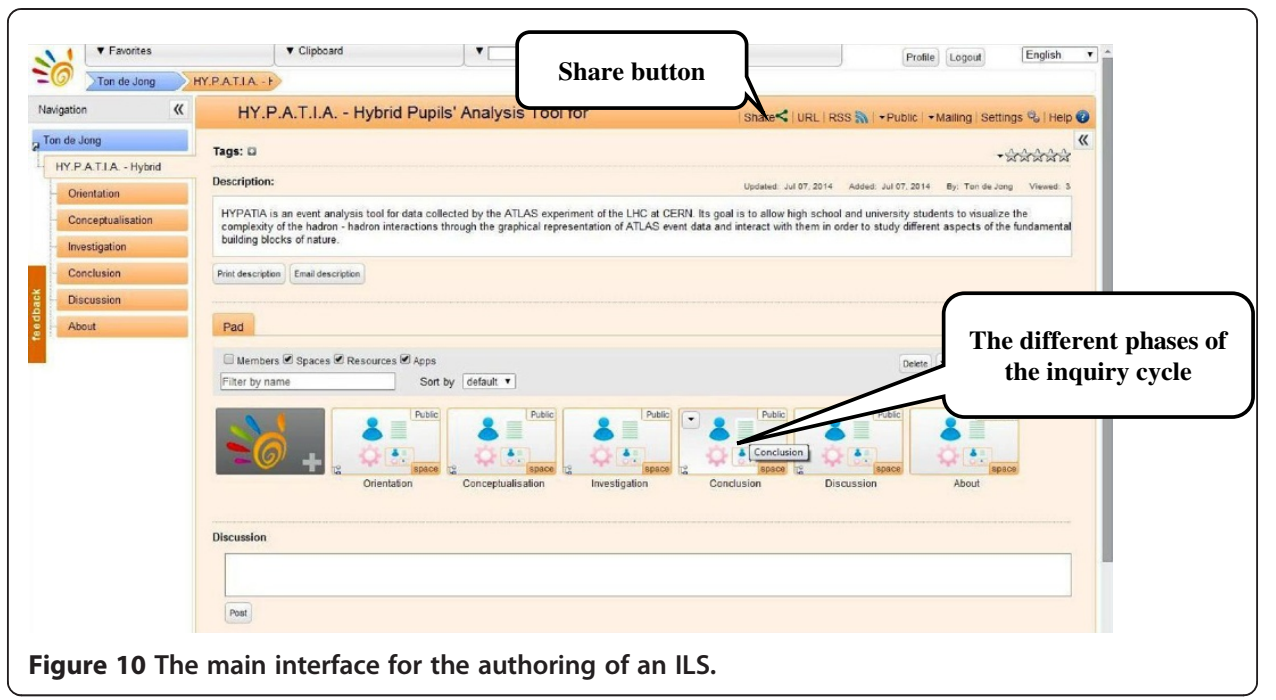

"About" space is for teachers only and may show background information about the design). Because this teacher started from the HYPATIA lab, this lab is already present in the investigation phase which becomes visible when this phase is opened. Teachers can remove, rename or add phases as they wish. By clicking on a phase, a wiki-like authoring environment is opened that allows the user to include and format texts, videos, weblinks, and so forth. In addition, scaffolds can be added to a phase simply by dragging them to the phase. The content of a scaffold (for example, the given terms in the hypothesis scratchpad scaffold) can be changed by opening the "app-composer" that allows changes in language and/or content. If a scaffold or tool is placed at the upper level (the "phases" level) it automatically appears in the bottom toolbar and it is then present in all phases. The authoring process is completed by clicking the share button. Clicking this button provides the teacher with a secret URL that can be given to the students and that displays a standalone ILS, such as is depicted in Figure 6.

Teachers who design an inquiry learning space, especially those who have no experience with inquiry, also need pedagogical support. In Go-Lab we offer this support through what we call inquiry scenarios. A Go-Lab scenario is a domain-independent description of a specific inquiry approach. We currently have identified four scenarios: the basic scenario following the Go-Lab inquiry cycle as explained before, a "changing hats" scenario in which students take different roles throughout the inquiry cycle, a "jigsaw approach", in which students in groups with changing compositions perform specific parts of the inquiry cycle and must collaborate to reach a result and the "critiquing" scenario in which students must criticize an inquiry process that has already been performed. This set of scenarios will be extended in the course of the project, but we will try to make the set of scenarios as small as possible in order to avoid overwhelming the teacher. The descriptions of these scenarios should also be brief so that a teacher may easily get a quick impression of their possibilities. If a teacher has found a suitable lab and wants to create his or her own ILS, the teacher can try to find to find a scenario that a) s/he likes b) fits his or her educational objectives c) fits his or her students' prior knowledge and inquiry skills d) can be organized in his or her classroom. 
After having selected a scenario, the teacher will be offered a default ILS in which the specific phases and the default filler for each phase are offered according to the scenario (and thus differs from the scenario as depicted in Figure 10). Then the teacher may continue by personalizing the available scaffolds (through the app composer) and adapt the default filling in of the phases for his own class, add or delete phases, and so forth. In addition, in what we call a "lesson plan", all kinds of information for collaborative or off-line activities that are characteristic for the scenario that was chosen will be offered. As an alternative to creating a new ILS or lesson plan from scratch (or rather from a default ILS or lesson plan), teachers may decide to continue working on existing ILSs or lesson plans that can be found on the Go-Lab portal. If a teacher has finished a self-created ILS or lesson plan, it can be uploaded to the portal under a creative commons license so that it can be used by other teachers.

\section{Go-Lab's technical infrastructure}

The technical infrastructure supporting the Go-Lab objectives builds on the outcome of previous European research projects such as PALETTE, in which an open access platform was developed to support online communities of practice, ROLE (Bogdanov et al., 2012) in which responsive open learning environments enabling recommendation (El Helou et al. 2010) and aggregation of cloud resources, peers, and Web applications were devised, and SCY (de Jong et al., 2010) in which scaffolding applications and virtual labs were developed and validated.

The Go-Lab portal is the single entry point for lab-owners and teachers to access the Go-Lab resources and services and integrates both the Go-Lab repository and the ILS authoring platform. The portal and the back-end services are implemented as loosely coupled components to enable a progressive and iterative development strategy with full user (pilot teacher) involvement, as described before. The loose coupling enables any platform or service to operate even when another component is unavailable. The front-end platforms include the Go-Lab repository based on Drupal, the ILS authoring facility based on Graasp, and the app composer enabling the translation and personalization of scaffolding apps or online lab interfaces, as well as the learning analytics workbench (Göhnert et al. 2013). The back-end services support lab-owners by enabling them to easily make remote labs available to the Go-Lab community, facilitate the harvesting of existing lab repositories, enable tracking of activities for learning analytics purposes, and offer add-ons to enable booking of remote labs and bartering of competencies for peer support within the teacher communities.

Several design principles have been devised and are enforced to strengthen the simplicity, the usability, and the sustainability of the Go-Lab technical infrastructure. First, the access to online labs through inquiry learning spaces is designed to be exploited as part of regular classroom activities. In such a context, collaboration between students happens face-to-face without technical mediation. Second, the Go-Lab platforms and services are loosely coupled, as mentioned above. Third, only libraries enabling responsive design (i.e., the user interface can adapt automatically to the devices used) and compatibility across devices are selected, to enable the exploitation of Go-Lab solutions either on desktop or laptop computers, as well as on tablets. Fourth, only modern Web standards such as HTML5 and Web sockets are exploited to enable the usage of modern Web browsers without the need to install dedicated plug-ins. In this spirit, 
educational standards linked to learning management systems and not compatible with the social media platforms learners are using nowadays are avoided. Fifth, no installation is required at school. The Go-Lab Portal is an open access platform that can be exploited by any teacher from anywhere at any time without requiring an authorization from a local school administration or actions by a local system administrator. Sixth, Web applications are developed using the opensocial standard and learning analytics rely on the activity stream standard, both to enable compatibility and portability across social media platforms and services (Chamberlain et al.). Last but not least, privacy is enforced by design. In Go-Lab, the privacy scheme mimics the model of the classroom, where only the teacher is aware of the identities and the activities of her or his students. As a consequence, privacy level is defined per inquiry learning space (ILS). The teacher can choose at the creation of the ILS whether tracking should be enabled or not, knowing that enabling it will offer better scaffolding for the students (scaffolding applications smoothly degrade their features depending on whether tracking is enabled or not). Students do not need an account to use an ILS shared by the teacher with a secret URL (which avoids malicious access to a space by external people). They simply log in using a nickname of their choice. This nickname is exploited internally for identifying the artifacts they created. The match between a nickname and a real identity is known only by the teacher and is not stored anywhere.

The proposed loosely coupled technical platforms and services together with the Go-Lab design principles have already enabled a smooth and progressive deployment of inquiry learning spaces to develop a shared understanding of the deployment challenges among the interdisciplinary partners in the project and with the initial pilot teachers. In the future, the social features of the portal will enable teachers to directly populate the repository with the ILSs they produce and help them to identify new resources based on their popularity (elicited through their usage, tagging, rating and commenting by peers), which will lower the barriers for sharing.

\section{Facilitating large-scale use of the Go-Lab portal}

The use of the Go-Lab portal and its services will be piloted and validated in a network of 1000 schools in Europe (Netherlands, Greece, Bulgaria, Romania, Belgium, Poland, Italy, Cyprus, Germany, Spain, Austria, Estonia, Switzerland, the UK and Portugal). The schools that are selected will have a different level of innovation maturity in order to provide a balanced sample. The most innovative of them operate in the framework of national (or local) reforms in the participating countries, while others offer nothing but the most basic services to their students. The 1000 pilot sites will be selected taking into consideration the local conditions and a set of common criteria, and will enter the project activities in three phases. The Go-Lab school network will include 100 innovative schools (in the use of technologies and in the application of innovative STEM practices) and 900 more mainstreamed school environments. Among them a sub-network of (about 100) remote and rural schools will be involved in the project, ensuring that all types of schools are represented in the pilot sample.

The aim of this effort is to generate a showcase of sufficient scale across borders, across languages, and across different educational systems. The organization of the 
large-scale pilots and the implementation of Go-Lab activities in a diverse group of schools in different European countries is a major challenge. The process requires the design of an implementation plan that takes into account the current reform initiatives of the different European countries. Different countries involve different cultures, curricula, and approaches, and thus the implementation of Go-Lab activities in each of them requires a different implementation plan tailored to their specific needs. However, Go-Lab implementation is taking advantage of the extended efforts regarding the effective introduction of inquiry-based approaches in STEM that are taking place in many European countries as a follow-up of the publication of the Rocard report (Rocard, et al,, 2007). For this reason, all implementation activities are centrally coordinated, but also managed locally by one partner in each of the pilot countries who will act as the National Coordinator, responsible for the local management and localization of resources and activities. Currently over 500 schools from all over Europe have subscribed to be involved the Go-Lab pilot phase.

\section{Conclusion}

The Go-Lab project is currently in the second year of its four year span. It has now laid the conceptual and technical basis for a federation of online labs, as discussed in this paper, and now goes on to a phase in which its facilities will be further tested, refined, and extended. A second major development will be the population of the portal and the creation of a large user community around the online labs. The facilities that Go-Lab offers for creating and sharing full learning environments around online labs should be one of the major "selling points" to attract lab-owners and teachers.

In this endeavor, it will be important to support teachers in the use of Go-Lab. Our experience with teachers until now has been that from a technical point of view, the way the Go-Lab authoring system is set up does not present them with major obstacles; teachers can very quickly create their first ILSs. This means that the main challenge will lie in informing teachers on how to create well-designed inquiry environments. Moving away from strictly guided procedural approaches when learning in labs or practical sessions will require a major shift in thinking. We hope that providing teachers with good examples of ILSs and default ILSs will be a source of inspiration.

The emphasis in our work on online laboratories doesn't mean that there is no room in the curriculum for other forms of instruction, such as physical laboratories, selfstudy, lectures, and so forth. All these forms of learning and instruction have their own specific advantages that should be part of a balanced curriculum, and often intelligent combinations, such as using virtual and physical labs together (see e.g., Jaakkola and Nurmi, 2008) offer specific advantages. Online labs can play a valuable role in this whole spectrum of instructional opportunities, and the intention is that the Go-Lab portal will contribute to realizing this role.

\section{Endnotes}

${ }^{a}$ Hereafter, when referring to science at large, we mean the natural sciences (physics, biology, chemistry, astronomy, geology, etc.), technology (including computer 
science), and math; also referred to as STEM (science, technology, engineering, and mathematics).

${ }^{\mathrm{b}}$ The Splash lab can be found at http://go-lab.gw.utwente.nl/production/splash/labs/ splash/virtual.html.

${ }^{c}$ The Methyl Orange lab can be accessed at https://www.chem.vu.nl/en/voor-het-vwo/ online-scheikunde-experiment/index.asp.

${ }^{\mathrm{d}}$ HYPATIA can be accessed at http://hypatia.iasa.gr/.

\section{Competing interests}

The authors declare that they have no competing interests.

\section{Authors' contributions}

$\mathrm{Td} J$ is the overall Go-Lab project coordinator and in addition responsible for the pedagogical part of the project, SS coordinates the implementation and communities aspects of Go-Lab, and DG is the technical coordinator of Go-Lab. All authors read and approved the final manuscript.

\section{Acknowledgement}

This work was partially funded by the European Union in the context of the Go-Lab project (Grant Agreement no. 317601) under the Information and Communication Technologies (ICT) theme of the 7th Framework Programme for R\&D (FP7. This document does not represent the opinion of the European Union, and the European Union is not responsible for any use that might be made of its content. We gratefully acknowledge the contributions of the many Go-Lab project members to the work presented here.

\section{Author details}

${ }^{1}$ Faculty of Behaviourial, Management \& Social sciences, University of Twente, PO Box 2177500 AE Enschede, The Netherlands. ${ }^{2}$ Research and Development Department, Ellinogermaniki Agogi, Dimitriou Panagea str., GR 15351 Pallini, Greece. ${ }^{3}$ School of Engineering, École polytechnique fédérale de Lausanne, Station 9 - EPFL - Ecublens, CH-1015 Lausanne, Switzerland.

Received: 5 May 2014 Accepted: 17 July 2014

Published: 16 October 2014

\section{References}

L Alfieri, PJ Brooks, NJ Aldrich, HR Tenenbaum, Does discovery-based instruction enhance learning? J. Educ. Psychol. 103, 1-18 (2011). doi:10.1037/a0021017

E Bogdanov, F Limpens, N Li, S El Helou, C Salzmann, D Gillet, A social media platform in higher education Proceedings of the IEEE engineering education conference (EDUCON), 2012, pp. 1-8

JM Chamberlain, K Lancastera, R Parson, KK Perkins, How guidance affects student engagement with an interactive simulation. Chem. Educ. Res. Prac. in press. doi:10.1039/C4RP00009A

Z Chen, D Klahr, All other things being equal: Acquisition and transfer of the control of variables strategy. Child Dev. 70, 1098-1120 (1999). doi:10.1111/1467-8624.00081

C d'Angelo, D Rutstein, C Harris, R Bernard, E Borokhovski, G Haertel, Simulations for STEM learning: Systematic review and meta-analysis (SRI International, Menlo Park, CA, 2014)

T de Jong, AW Lazonder, The guided discovery principle in multimedia learning, in The Cambridge handbook of multimedia learning, ed. by RE Mayer, JJG van Merriënboer, W Schnotz, J Elen, 2nd edn. (Cambridge University Press, Cambridge, 2014), pp. 371-390

T de Jong, MC Linn, ZC Zacharia, Physical and virtual laboratories in science and engineering education. Science 340, 305-308 (2013). doi:10.1126/science.1230579

T de Jong, WR van Joolingen, A Giemza, I Girault, U Hoppe, J Kindermann, AW Kluge, AW Lazonder, V Vold, A Weinberger, S Weinbrenner, A Wichmann, A Anjewierden, M Bodin, L Bollen, C d'Ham, J Dolonen, J Engler, C Geraedts, H Grosskreutz, T Hovardas, R Julien, J Lechner, S Ludvigsen, Y Matteman, Ø Meistadt, B Næss, M Ney, M Pedaste, A Perritano, et al., Learning by creating and exchanging objects: The SCY experience. Br. J. Educ. Technol. 41, 909-921 (2010). doi:10.1111/j.1467-8535.2010.01121.x

S El Helou, C Salzmann, D Gillet, The 3a personalized, contextual and relation-based recommender system. J. Universal Comput. Sci. 16, 2179-2195 (2010)

THS Eysink, T de Jong, K Berthold, B Kolloffel, M Opfermann, P Wouters, Learner performance in multimedia learning arrangements: An analysis across instructional approaches. Am. Educ. Res. J. 46, 1107-1149 (2009). doi:10.3102/ 0002831209340235

EM Furtak, T Seidel, H Iverson, DC Briggs, Experimental and quasi-experimental studies of inquiry-based science teaching. Rev. Educ. Res. 82, 300-329 (2012). doi:10.3102/0034654312457206

T Göhnert, A Harrer, T Hecking, HA Hoppe, A workbench to construct and re-use network analysis workflows: Concept implementation, and example case, in Proceedings of the 2013 IEEE/ACM international conference on advances in social networks analysis and mining, 2013, pp. 1464-1466

W Harlen (ed.), Principles and big ideas of science education (Association for Science Education, Hatfield, Herts, 2010)

T Jaakkola, S Nurmi, Fostering elementary school students' understanding of simple electricity by combining simulation and laboratory activities. J. Comput. Assist. Learn. 24, 271-283 (2008). doi:10.1111/j.1365-2729.2007.00259.x

C Kourkoumelis, S Vourakis, HYPATIA—an online tool for ATLAS event visualization. Phys. Educ. 49, 21-32 (2014) 
J Künsting, J Kempf, J Wirth, Enhancing scientific discovery learning by metacognitive support. Contemp. Educ. Psychol. 349-360 (2013). doi:10.1016/j.cedpsych.2013.07.001

E Law, Preliminary Go-Lab requirements specifications, needs analysis, and creative options (deliverable d3.1): Go-Lab Consortium, 2013

MC Linn, H-S Lee, R Tinker, F Husic, JL Chiu, Teaching and assessing knowledge integration in science. Science 313, 1049-1050 (2006). doi:10.1126/science.1131408

National Research Council, America's lab report: Investigations in high school science (National Academy Press, Washington, DC, 2006)

National Science Foundation, An introduction to inquiry Foundations, in Inquiry: Thoughts, views and strategies for the k-5 classroom, Vol. 2nd edn., 2000, pp. 1-5

JL Plass, C Milne, BD Homer, RN Schwartz, EO Hayward, T Jordan, J Barrientos, Investigating the effectiveness of computer simulations for chemistry learning. J. Res. Sci. Teach. 49, 394-419 (2012). doi:10.1002/tea.21008

M Rocard, P Csermely, D Jorde, D Lenzen, H Walberg-Henrikson, V Hemmo, Science education now: A renewed pedagogy for the future of Europe (European Commission: Directorate-General for Research, Brussels, 2007)

WR van Joolingen, T de Jong, Supporting hypothesis generation by learners exploring an interactive computer simulation. Instr. Sci. 20, 389-404 (1991). doi:10.1007/BF00116355

L van Rens, H van Dijk, J Mulder, P Nieuwland, Using a web application to conduct and investigate syntheses of methyl orange remotely. J. Chem. Educ. 90, 574-577 (2013). doi:10.1021/ed300719q

MM Waldrop, The virtual lab. Nature 499, 268-270 (2013). doi:10.1038/499268a

CE Wieman, WK Adams, KK Perkins, PhET: Simulations that enhance learning. Science 322, 682-683 (2008). doi:10.1126/ science. 1161948

J Zhang, Q Chen, Y Sun, DJ Reid, Triple scheme of learning support design for scientific discovery learning based on computer simulation: Experimental research. J. Comput. Assist. Learn. 20, 269-282 (2004). doi:10.1111/j.13652729.2004.00062x

doi:10.1186/s40561-014-0003-6

Cite this article as: de Jong et al:: Innovations in STEM education: the Go-Lab federation of online labs. Smart Learning Environments 2014 1:3.

\section{Submit your manuscript to a SpringerOpen ${ }^{\circ}$ journal and benefit from:}

- Convenient online submission

- Rigorous peer review

- Immediate publication on acceptance

- Open access: articles freely available online

- High visibility within the field

- Retaining the copyright to your article

Submit your next manuscript at $\boldsymbol{\sim}$ springeropen.com 